\title{
Does the lipid-lowering peroxisome proliferator-activated receptors ligand bezafibrate prevent colon cancer in patients with coronary artery disease?
}

\author{
Alexander Tenenbaum ${ }^{1}$, Valentina Boyko², Enrique Z Fisman*1, \\ Ilan Goldenberg'2, Yehuda Adler' ${ }^{1}$, Micha S Feinberg ${ }^{1}$, Michael Motro', \\ David Tanne ${ }^{2}$, Joseph Shemesh ${ }^{1}$, Ehud Schwammenthal ${ }^{1}$ and \\ Solomon Behar ${ }^{2}$
}

Address: ${ }^{1}$ Cardiac Rehabilitation Institute, the Chaim Sheba Medical Center, Tel-Hashomer, affiliated with the Sackler Faculty of Medicine, TelAviv University, Tel-Aviv, Israel and ${ }^{2}$ Bezafibrate Infarction Prevention Study Coordinating Center, Neufeld Cardiac Research Institute, the Chaim Sheba Medical Center, Tel-Hashomer, affiliated with the Sackler Faculty of Medicine, Tel-Aviv University, Tel-Aviv, Israel

Email: Alexander Tenenbaum - altenen@post.tau.ac.il; Valentina Boyko - valentina.boyko@sheba.health.gov.il; Enrique Z Fisman* - zfisman@post.tau.ac.il; Ilan Goldenberg - Ilan.Goldenberg@heart.rochester.edu; Yehuda Adler - adlery@post.tau.ac.il; Micha S Feinberg - micha.feinberg@sheba.health.gov.il; Michael Motro - michaelmotro@yahoo.com; David Tanne - tanne@post.tau.ac.il; Joseph Shemesh - joseph.shemesh@sheba.health.gov.il; Ehud Schwammenthal - ehud.schwammenthal@sheba.health.gov.il; Solomon Behar - behar@sheba.health.gov.il

* Corresponding author

Published: 19 June 2008

Cardiovascular Diabetology 2008, 7:18 doi:10.1 I86/1475-2840-7-18

This article is available from: http://www.cardiab.com/content/7////8

(c) 2008 Tenenbaum et al; licensee BioMed Central Ltd.

This is an Open Access article distributed under the terms of the Creative Commons Attribution License (http://creativecommons.org/licenses/by/2.0), which permits unrestricted use, distribution, and reproduction in any medium, provided the original work is properly cited.
Received: 7 June 2008

Accepted: 19 June 2008

\begin{abstract}
Background: Epidemiologic studies have suggested that hypertriglyceridemia and insulin resistance are related to the development of colon cancer. Nuclear peroxisome proliferator-activated receptors (PPAR), which play a central role in lipid and glucose metabolism, had been hypothesized as being involved in colon cancerogenesis. In animal studies the lipid-lowering PPAR ligand bezafibrate suppressed colonic tumors. However, the effect of bezafibrate on colon cancer development in humans is unknown. Therefore, we proposed to investigate a possible preventive effect of bezafibrate on the development of colon cancer in patients with coronary artery disease during a 6-year follow-up.
\end{abstract}

Methods: Our population included 30II patients without any cancer diagnosis who were enrolled in the randomized, double blind Bezafibrate Infarction Prevention (BIP) Study. The patients received either $400 \mathrm{mg}$ of bezafibrate retard (I 506 patients) or placebo (I505 patients) once a day. Cancer incidence data were obtained by matching a subject's identification numbers with the National Cancer Registry. Each matched record was checked for correct identification.

Results: Development of new cancer (all types) was recorded in 177 patients: in 79 (5.25\%) patients from the bezafibrate group vs. $98(6.5 \mathrm{l} \%)$ from the placebo group. Development of colon cancer was recorded in 25 patients: in $8(0.53 \%)$ patients from the bezafibrate group vs. 17 (I.I3\%) from the placebo group, (Fisher's exact test: one side $p=0.05$; two side $p=0.07$ ).

A difference in the incidence of cancer was only detectable after a 4 year lag and progressively increased with continued followup. On multivariable analysis the colon cancer risk in patients who received bezafibrate tended to be lower with a hazard ratio of 0.47 and $95 \%$ confidence interval $0.2-1.1$.

Conclusion: Our data, derived from patients with coronary artery disease, support the hypothesis regarding a possible preventive effect of bezafibrate on the development of colon cancer. 


\section{Background}

Colon cancer is one of the leading forms of malignancy in the developed countries. Epidemiologic and animal studies have suggested that risk factors for coronary artery disease like insulin resistance and dyslipidemia are probably related to the development of colon cancer [1-7]. Particularly, nuclear peroxisome proliferator-activated receptors (PPAR), mainly alpha and gamma, which play a central role in lipid and glucose metabolism, had been hypothesized as being involved in colon cancerogenesis [8-12]. Furthermore, synthetic PPAR ligands (glitazones and bezafibrate) with proven beneficial effects on insulin resistance and triglyceride levels had been proposed to be candidates as tumor preventive agents [12-14].

While dietary administration of pan-PPAR ligand bezafibrate has been demonstrated to suppress the development of colonic tumors in rodents [12-14], its effect on colon cancer development in humans is unknown. We therefore sought to investigate a potential preventive effect of bezafibrate on the development of colon cancer in patients with coronary artery disease enrolled in the randomized, double blind Bezafibrate Infarction Prevention (BIP) Study.

\section{Methods}

The major inclusion and exclusion criteria for the BIP study, as well as the ethical guidelines, have been previously reported [15]. In brief, inclusion criteria for men and women comprised: age 45-74 years, history of myocardial infarction no less than 6 months and not more than 5 years prior to enrollment into the study and/or stable angina pectoris. The major exclusion criteria for the BIP study were: malignant diseases, permanent pacemaker implantation, cerebrovascular disease, chronic hepatic or renal disease, peripheral vascular disease, estrogen replacement therapy, insulin dependent diabetes mellitus and current use of a lipid modifying drug.

There were 3090 patients who were included in the BIP study after screening. Patients in whom a diagnosis of cancer had been made after screening but before the launch of the study medication as well as patients with unknown vital status were excluded from this analysis. Thus, the final study sample for our study comprised 3011 patients.

The patients received either $400 \mathrm{mg}$ of bezafibrate retard or placebo once a day. Patients continued their prescribed medications for cardiac and other conditions except lipid lowering drugs. The primary endpoint of the BIP study was fatal or non-fatal MI or sudden death (combined major cardiovascular events).

Cancer incidence data were obtained by matching a subject's personal identification number (PID) with the Israel
National Cancer Registry (INCR). Each matched record was checked for correct identification.

The detailed description of INCR has been published previously [16]. In summary, the INCR is a population-based central tumor registry established in 1960 and since 1982 reporting to the registry is mandatory [17]. All medical facilities, both public and private and pathology laboratories that are diagnosing or treating cancer patients send a copy of their medical summary which contains tumor characteristics to the Registry. The INCR also collects data on cancer deaths from District Health Authorities and the Central Population Registry. In Israel, all demographic data are stored in the Central Population Registry in accordance with PID. The INCR is linked to this Registry and each cancer patient's personal data are then retrieved and validated. The last audit of data completeness concluded that registration was above 95\% [18].

The mean follow-up period of the BIP study was $6.2 \pm 0.8$, range 4.7 to 7.6 years. The trial was conducted independently of the sponsor (Boehringer Mannheim $\mathrm{GmbH}$, which is now part of F. Hoffmann-La Roche, Ltd), and it was approved by the Helsinki Committees of each center and the central national Helsinki Committee.

Data were analyzed using the SAS software, version 8.2 (SAS Institute Inc., Cary, NC, USA). Continuous variables at baseline were presented as mean values \pm standard deviation (SD). Comparisons between groups were made using chi-square tests for discrete variables and Student ttest or Wilcoxon rank sum test for continuous variables. A $p$-value of less than 0.05 was considered as statistically significant.

Kaplan-Meier curves were produced using the LIFETEST procedure. The log-rank test was used for comparing the curves.

Multivariable analysis of the incidence of colon cancer was performed using the Cox proportional hazard model (PHREG procedure) to account for differing lengths of follow-up and correlation with covariates. Hazard ratio (HR) and $95 \%$ confidence interval (CI) for new colon cancer was calculated. Variables included in the models were age, gender, total cholesterol, In transformed triglycerides, smoking status, study medication and body mass index (BMI).

\section{Results}

\section{Baseline data}

Our population included 2 groups: 1) Bezafibrate group 1506 patients; 2) Placebo group - 1505 patients. 
Table I: Baseline characteristics of the study population.

\begin{tabular}{|c|c|c|c|}
\hline Characteristics & Bezafibrate $(n=1506)$ & Placebo $(n=1505)$ & p value \\
\hline Age (years) & $60.0 \pm 6.8$ & $60.0 \pm 6.7$ & 0.9 \\
\hline Body mass index $(\mathrm{kg} / \mathrm{m} 2)$ & $26.7 \pm 3.3$ & $26.7 \pm 3.3$ & 0.7 \\
\hline Men (\%) & $1374(9 \mid)$ & $1382(92)$ & 0.6 \\
\hline Past myocardial infarction (\%) & $1184(79)$ & $1163(77)$ & 0.3 \\
\hline Angina (\%) & $848(56)$ & $876(58)$ & 0.3 \\
\hline NYHA Class $\geq 2(\%)$ & $45(27)$ & $47(26)$ & 0.9 \\
\hline Hypertension (\%) & $462(31)$ & $507(34)$ & 0.1 \\
\hline Current smokers & $177(12)$ & $184(12)$ & 0.7 \\
\hline Systolic blood pressure $(\mathrm{mmHg})$ & $134 \pm 18$ & $133 \pm 18$ & 0.3 \\
\hline Diastolic blood pressure $(\mathrm{mmHg})$ & $81.1 \pm 9.0$ & $80.8 \pm 9.1$ & 0.4 \\
\hline Heart rate (beats/min) & $70.1 \pm 9.3$ & $70.0 \pm 9.3$ & 0.8 \\
\hline Total cholesterol (mg/dl) & $211 \pm 17$ & $213 \pm 18$ & 0.2 \\
\hline HDL-cholesterol (mg/dl) & $34.5 \pm 5.5$ & $34.6 \pm 5.5$ & 0.7 \\
\hline LDL-cholesterol (mg/dl) & $148 \pm 16$ & $149 \pm 16$ & 0.2 \\
\hline Triglycerides (mg/dl) & $|45 \pm 5|$ & $|45 \pm 5|$ & 0.9 \\
\hline Fibrinogen (mg/dl) & $350 \pm 72$ & $351 \pm 74$ & 0.7 \\
\hline
\end{tabular}

Patients in the placebo and bezafibrate groups were well balanced in terms of clinical and laboratory baseline characteristics (Table 1). The study groups were similar in regard to age, gender and the prevalence of the most relevant cardiovascular diseases and risk factors (a myocardial infarction in the past, hypertension, diabetes, heart failure, anginal syndrome). The majority of the patients in all groups were men who had sustained a myocardial infarction in the past. No significant differences between the groups were found for all types of cholesterol, systolic and diastolic blood pressure, heart rate, body mass index, fasting glucose, triglycerides and fibrinogen levels. At baseline, nitrates, calcium antagonists, beta blockers and antiplatelet drugs (mainly aspirin) were the most commonly used medications. There were no significant differences between the groups in the proportion of patients receiving other cardiovascular drugs.

\section{Clinical outcomes}

During the follow-up period, development of new cancer (all types) was recorded in 177 patients: in 79 (5.25\%) patients from the bezafibrate group vs. 98 (6.51\%) from the placebo group $(\mathrm{p}=0.14)$. Development of new colon cancer was recorded in 25 patients (Figure 1): in 8 $(0.53 \%)$ patients from the bezafibrate group vs. 17 $(1.13 \%)$ from the placebo group, (Fisher's exact test: one side $\mathrm{p}=0.05$; two side $\mathrm{p}=0.07$ ).

Kaplan-Meier curves of colon cancer incidence (in accordance with the time of diagnosis) for the two study groups are presented in Figure 2. The incidence rate of patients on placebo tended to be higher than in their bezafibrate treated counterparts, ( $p$ log-rank $=0.07)$. A difference in the incidence of cancer was only detectable after a 4 year lag and progressively increased with continued follow-up.
On multivariable analysis the colon cancer risk in patients received bezafibrate tended to be lower with a hazard ratio of 0.47 and $95 \%$ confidence interval $0.2-1.1$.

\section{Discussion}

The main novel finding in this post hoc analysis of the BIP study, which was randomized and double blind in design, is a possible preventive effect of bezafibrate on the development of colon cancer in humans. The study hypothesis is supported not only by the magnitude of colon cancer risk reduction in patients treated by bezafibrate (53\%), but, more importantly by the time-course of the KaplanMeier curves: The 4 year lag in the occurrence of detectable

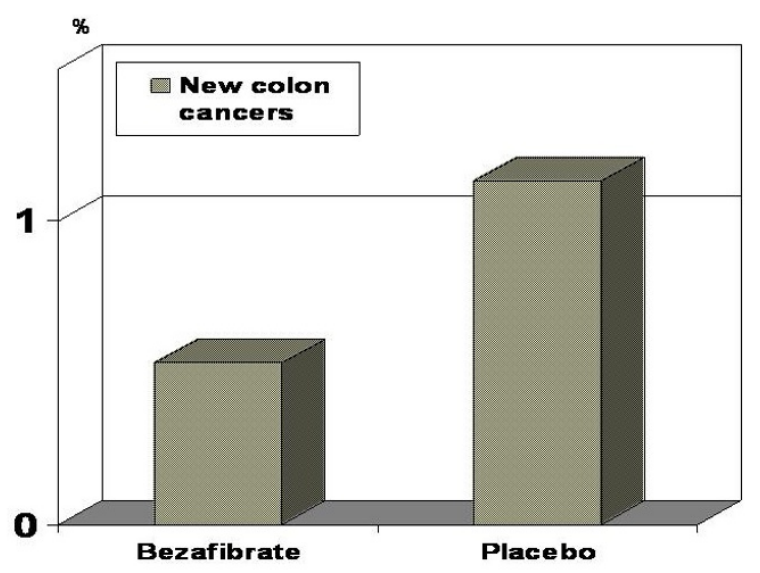

\section{Figure I}

New colon cancers (\%) during follow-up; bezafibrate vs. placebo (Fisher's exact test: one side $p=0.05$; two side $p=$ 0.07). 


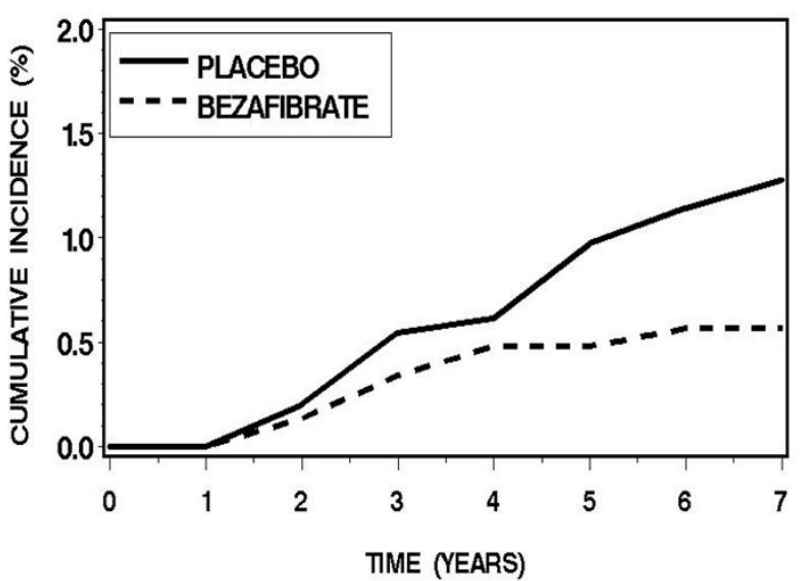

Figure 2

Kaplan-Meier curves of colon cancer incidence (in accordance with the time of diagnosis) for the study groups (bezafibrate vs. placebo; 6.2 years mean follow-up, $\mathrm{p}$ log-rank $=$ 0.07).

differences between groups, followed by a progressive disparity in colon cancer incidence between patients on bezafibrate and patients on placebo are characteristic of a biologic effect and thus support causality rather than chance association.

Accumulating animal experimental, human laboratory and epidemiologic data $[6,10-14,19,20]$ support the hypothesis linking triglyceride levels and insulin resistance to the development of colon cancer. These facts emphasize the potential for this cancer to become a preventable disease not only via screening and removal of polyps but through relevant lifestyle changes and pharmacological interventions which can provide even more avenues for prevention [19-25].

The fact that the incidence of insulin resistance has been increasing in the Western world where colon cancer is the second leading cause of cancer death makes the exploration of the interrelationship of these conditions a subject of high priority for public health.

The biological role of the peroxisome proliferator-activated receptors (PPARs) in various diseases, including inflammation and cancer, has been highlighted recently [8-14,26-28]. PPARs are members of the nuclear hormone receptor family of ligand-activated transcription factors that play a prominent role in the regulation of many metabolic processes. The alpha and gamma isoforms of PPAR are important regulators in lipid and glucose metabolism, cell differentiation and inflammatory response [29,30]. These data propose that PPAR alpha, beta/delta and gamma may be associated with many aspects of colon cancer development including insulin- and inflammation-related mechanisms.

The fibric acid derivative bezafibrate is the pan - (alpha, beta/delta, gamma) PPAR activator with predominantly PPAR alpha (as all fibrates) and beta/delta effects but also with perceptible PPAR gamma properties [31-36]. The use of bezafibrate is associated with triglyceride-lowering and HDL-cholesterol raising effects resulting in decreased systemic availability of fatty acid, diminished of fatty acid uptake by muscle and improvement of insulin sensitization $[37,38]$. These direct and indirect effects may have contributed to the suppression of the development of colonic tumors in rodents by bezafibrate [12-14].

\section{Limitations of the study}

Although development of new colon cancer in patients randomized to bezafibrate was more than half as frequent as in those randomized to placebo, the difference reached only borderline statistical significance. The BIP study was designed (both in terms of sample size and time of followup) to detect the effect of the lipid-modifying agent bezafibrate on major cardiovascular events in coronary patients at high risk, but had not an appropriate statistical power to explore development of such a relatively low-incidence disease as colon cancer. In addition, caution should be used in interpreting our findings, as they were identified in post-hoc analysis.

However, the detected pattern of the time course in the differences between groups, suggesting a biologically meaningful effect, is encouraging and supports the initiation of a large prospective controlled trial in light of its importance for public health.

\section{Conclusion}

The use of bezafibrate as lipid-modifying agent in patients with coronary artery disease appears to be associated with a reduced risk of colon cancer.

\section{Competing interests}

The authors declare that they have no competing interests.

\section{Authors' contributions}

AT conceived the study and drafted the manuscript, EZF, YA and SB were involved in the study design, coordination and data acquisition, $\mathrm{AT}, \mathrm{VB}$ and $\mathrm{SB}$ studied and matched the records from the Cancer Registry, EZF, IG, ES, JS and MSF interpreted the results and VB performed the statistical analysis of the data presented, EZF, DT, SB, ES, MSF and MM critically reviewed the study for important intellectual content. All authors approved the final version of the manuscript. 


\section{Acknowledgements}

This work was supported in part by the Cardiovascular Diabetology Research Foundation (RA 58-040-684-I), Holon, Israel, and the Research Authority of Tel-Aviv University.

\section{References}

I. Mutoh M, Niho N, Wakabayashi K: Concomitant suppression of hyperlipidemia and intestinal polyp formation by increasing lipoprotein lipase activity in Apc-deficient mice. Biol Chem 2006, 387:38I-385.

2. Komninou D, Ayonote A, Richie JP Jr, Rigas B: Genomics, transcriptomics, proteomics, and numbers. Arch Pathol Lab Med 2003, 127:1089-1097.

3. Giovannucci E: Insulin and colon cancer. Cancer Causes Control 1995, 6:164-179.

4. McKeown-Eyssen G: Epidemiology of colorectal cancer revisited: are serum triglycerides and/or plasma glucose associated with risk? Cancer Epidemiol Biomarkers Prev 1994, 3:687-695.

5. Tabuchi M, Kitayama J, Nagawa $\mathrm{H}$ : Hypertriglyceridemia is positively correlated with the development of colorectal tubular adenoma in Japanese men. World J Gastroenterol 2006, 12:126I-1264

6. Bruce WR, Wolever TM, Giacca A: Mechanisms linking diet and colorectal cancer: the possible role of insulin resistance. Nutr Cancer 2000, 37: 19-26.

7. Yamada K, Araki S, Tamura M, Sakai I, Takahashi Y, Kashihara H, Kono S: Relation of serum total cholesterol, serum triglycerides and fasting plasma glucose to colorectal carcinoma in situ. Int J Epidemiol 1998, 27:794-798.

8. Slattery ML, Curtin K, Wolff R, Ma KN, Sweeney C, Murtaugh M, Potter JD, Levin TR, Samowitz W: PPARgamma and colon and rectal cancer: associations with specific tumor mutations, aspirin, ibuprofen and insulin-related genes (United States). Cancer Causes Control 2006, 17:239-249.

9. Tanaka T, Kohno H, Yoshitani S, Takashima S, Okumura A, Murakami A, Hosokawa M: Ligands for peroxisome proliferator-activated receptors alpha and gamma inhibit chemically induced colitis and formation of aberrant crypt foci in rats. Cancer Res 200I, 6I:2424-2428.

10. Matthiessen MW, Pedersen G, Albrektsen T, Adamsen S, Fleckner J, Brynskov J: Peroxisome proliferator-activated receptor expression and activation in normal human colonic epithelial cells and tubular adenomas. Scand J Gastroenterol 2005, 40:198-205.

11. Rosen ED, Spiegelman BM: PPARgamma: a nuclear regulator of metabolism, differentiation, and cell growth. J Biol Chem 200I, 276:3773I-37734

12. Niho N, Takahashi M, Kitamura T, Shoji Y, Itoh M, Noda T, Sugimura T, Wakabayashi K: Concomitant suppression of hyperlipidemia and intestinal polyp formation in Apc-deficient mice by peroxisome proliferator-activated receptor ligands. Cancer Res 2003, 63:6090-6095

13. Kohno H, Suzuki R, Sugie S, Tanaka T: Suppression of colitisrelated mouse colon carcinogenesis by a COX-2 inhibitor and PPAR ligands. BMC Cancer 2005, 5:46.

14. Tanaka T, Kohno H, Yoshitani S, Takashima S, Okumura A, Murakami A, Hosokawa M: Ligands for peroxisome proliferator-activated receptors alpha and gamma inhibit chemically induced colitis and formation of aberrant crypt foci in rats. Cancer Res 200I, $61: 2424-2428$.

15. Secondary prevention by raising HDL cholesterol and reducing triglycerides in patients with coronary artery disease: the Bezafibrate Infarction Prevention (BIP) study. Circulation 2000, 102:2I-27.

16. Barchana M, Liphshitz I, Rozen P: Trends in colorectal cancer incidence and mortality in the Israeli Jewish ethnic populations. Fam Cancer 2004, 3:207-2I4.

17. Israel Cancer Registry - 19972001 [http://www.health.gov.il/ pages/default.asp?maincat $=22$ ]. Jerusalem, Israel: Ministry of Health February 25, 2008

18. Fishler Y, Chitrit A, Barchana M, Modan B: Examination of Israel national cancer data accumulation completeness for 1991. The National Center for Disease Control, Publication No. 230, Tel Hashomer, Israel 2003.
19. Colangelo LA, Gapstur SM, Gann PH, Dyer AR, Liu KL: Colorectal cancer mortality and factors related to the insulin resistance syndrome. Cancer Epidemiol Biomarkers Prev 2002, I I:385-39I.

20. Trevisan M, Liu J, Muti P, Misciagna G, Menotti A, Fucci F: Markers of insulin resistance and colorectal cancer mortality. Cancer Epidemiol Biomarkers Prev 200I, 10:937-94I.

21. Schoen RE, Tangen CM, Kuller LH, Burke GL, Cushman M, Tracy RP, Dobs A, Savage PJ: Increased blood glucose and insulin, body size, and incident colorectal cancer. J Natl Cancer Inst 1999, 91: I I47-II54.

22. Morita T, Tabata S, Mineshita M, Mizoue T, Moore MA, Kono S: The metabolic syndrome is associated with increased risk of colorectal adenoma development: the Self-Defense Forces health study. Asian Pac J Cancer Prev 2005, 6:485-489.

23. Cowey S, Hardy RW: The metabolic syndrome: A high-risk state for cancer? Am J Pathol 2006, 169:1505-1522.

24. Nilsen TI, Vatten LJ: Prospective study of colorectal cancer risk and physical activity, diabetes, blood glucose and BMI: exploring the hyperinsulinaemia hypothesis. BrJ Cancer 200I, 84:417-422.

25. Giovannucci E: Insulin, insulin-like growth factors and colon cancer: a review of the evidence. J Nutr 200I, 13 I:3 I09S-3 I20S.

26. Peroxisome proliferator-activated receptor gamma: a novel target for cancer therapeutics? Anticancer Drugs 2007, 18:237-244

27. Thompson EA: PPARgamma physiology and pathology in gastrointestinal epithelial cells. Mol Cells 2007, 24:167-I76.

28. Hollingshead HE, Borland MG, Billin AN, Willson TM, Gonzalez FJ, Peters JM: Ligand activation of peroxisome proliferator-activated receptor-\{beta\}/\{delta\} (PPAR $\{$ beta\}/\{delta\}) and inhibition of cyclooygenase-2 (COX2) attenuate colon carcinogenesis through independent signaling mechanisms. Carcinogenesis 2008, 29:169-176.

29. Tenenbaum A, Fisman EZ, Motro M: Metabolic syndrome and type 2 diabetes mellitus: focus on peroxisome proliferator activated receptors (PPAR). Cardiovasc Diabetol 2003, 2:4.

30. Libby P, Plutzky J: Inflammation in diabetes mellitus: role of peroxisome proliferator-activated receptor-alpha and peroxisome proliferator-activated receptor-gamma agonists. Am J Cardiol 2007, 99(4A):27B-40B.

31. Tenenbaum A, Motro M, Fisman EZ: Dual and pan-peroxisome proliferator-activated receptors (PPAR) co-agonism: the bezafibrate lessons. Cardiovasc Diabetol 2005, 4:I4.

32. Willson TM, Brown PJ, Sternbach DD, Henke BR: The PPARs: from orphan receptors to drug discovery. J Med Chem 2000, 43:527-550.

33. Peters JM, Aoyama T, Burns AM, Gonzalez FJ: Bezafibrate is a dual ligand for PPARalpha and PPARbeta: studies using null mice. Biochim Biophys Acta 2003, 1632:80-89.

34. Poirier H, Rouault C, Clément L, Niot I, Monnot MC, Guerre-Millo $M$, Besnard P: Differential involvement of peroxisome-proliferator-activated receptors alpha and delta in fibrate and fattyacid-mediated inductions of the gene encoding liver fattyacid-binding protein in the liver and the small intestine. Biochem J 200I, 355:48I-488.

35. Vázquez M, Roglans N, Cabrero A, Rodríguez C, Adzet T, Alegret M, Sánchez RM, Laguna JC: Bezafibrate induces acyl-CoA oxidase mRNA levels and fatty acid peroxisomal beta-oxidation in rat white adipose tissue. Mol Cell Biochem 200I, 216:7I-78.

36. Nagasawa $T$, Inada $Y$, Nakano $S$, Tamura $T$, Takahashi $T$, Maruyama K, Yamazaki Y, Kuroda J, Shibata N: Effects of bezafibrate, PPAR pan-agonist, and GW50 PPARdelta agonist, on development of steatohepatitis in mice fed a methionine- and choline-deficient diet. Eur J Pharmacol I5|6, 536( I-2): |82-9|.

37. Tenenbaum A, Motro M, Fisman EZ, Schwammenthal E, Adler $Y$, Goldenberg I, Leor J, Boyko V, Mandelzweig L, Behar S: Peroxisome proliferator-activated receptors ligand bezafibrate for prevention of type 2 diabetes mellitus in patients with coronary artery disease. Circulation 2004, 109:2197-2202.

38. Despres JP, Lemieux I, Robins SJ: Role of fibric acid derivatives in the management of risk factors for coronary heart disease. Drugs 2004, 64:2177-2198. 